ARTICLE

\title{
Waveguide photoreactor enhances solar fuels photon utilization towards maximal optoelectronic - photocatalytic synergy
}

\author{
Joel Y. Y. Loh', Abhinav Mohan ${ }^{2}$, Andrew G. Flood ${ }^{1}$, Geoffery A. Ozin (D) ${ }^{2,4 凶}$ \& Nazir P. Kherani ${ }^{1,3,4 凶}$
}

A conventional light management approach on a photo-catalyst is to concentrate photointensity to enhance the catalytic rate. We present a counter-intuitive approach where light intensity is distributed below the electronic photo-saturation limit under the principle of light maximization. By operating below the saturation point of the photo-intensity induced hydroxide growth under reactant gaseous $\mathrm{H}_{2}+\mathrm{CO}_{2}$ atmosphere, a coating of defect engineered $\ln _{2} \mathrm{O}_{3-x}(\mathrm{OH})_{y}$ nanorod Reverse Water Gas Shift solar-fuel catalyst on an optical waveguide outperforms a coated plane by a factor of 2.2. Further, light distribution along the length of the waveguide increases optical pathlengths of the weakly absorptive green and yellow wavelengths, which increases $\mathrm{CO}$ product rate by a factor of 8.1-8.7 in the visible. Synergistically pairing with thinly doped silicon on the waveguide enhances the $\mathrm{CO}$ production rate by $27 \%$ over the visible. In addition, the persistent photoconductivity behavior of the $\mathrm{In}_{2} \mathrm{O}_{3-x}(\mathrm{OH})_{y}$ system enables $\mathrm{CO}$ production at a comparable rate for $2 \mathrm{~h}$ after turning off photo-illumination, enhancing yield with 44-62\% over thermal only yield. The practical utility of persistent photocatalysis was demonstrated through outdoor solar concentrator tests, which after a day-and-night cycle showed CO yield increase of $19 \%$ over a day-light only period.

\footnotetext{
${ }^{1}$ Department of Electrical and Computing Engineering, University of Toronto, 10 King's College Road, Toronto, ON M5S 3G4, Canada. ${ }^{2}$ Department of Chemistry, University of Toronto, 80 St. George Street, Toronto, ON M5S 3H6, Canada. ${ }^{3}$ Department of Materials Science and Engineering, University of Toronto, 140 College Street, Toronto, ON M5S 3E4, Canada. ${ }^{4}$ These authors jointly supervised this work: Geoffrey A. Ozin, Nazir P. Kherani.

凶email: g.ozin@utoronto.ca; kherani@ecf.utoronto.ca
} 
$\mathrm{D}$ isplacing the fossil fuel industry with the goal of climate change mitigation and environmental preservation requires a carbon-neutral solar fuels catalysis cycle from product to reactants and vice versa. The conversion of solar radiation to solar fuels such as carbon monoxide to be further processed as methanol ${ }^{1}$ is a thermodynamically more feasible and potentially high yielding ${ }^{2}$ than direct $\mathrm{CO}_{2}$ hydrogenation ${ }^{3-5}$.

However, the conventional tendency in order to maximize a photo-catalyst product rate is to concentrate the incident light intensity with the assumption that the reaction rate is dependent on the density of excited charge carriers ${ }^{6,7}$. Since the volumetric photo-generated electron-hole density far exceeds the possible concentration of surface active sites, photon-to-charge-to-yield efficiencies are poor at high photon intensities due to increasingly high rates of recombination processes ${ }^{8}$, which results in a semisaturation limit ${ }^{9}$. The contradiction between achieving high photon-to-yield efficiencies (for maximizing the size of solar coverage) and high product rate (for maximizing the yield per catalyst mass or area) requires light to a catalyst management approach that encompasses both optical and charges based catalysis considerations ${ }^{10}$.

Herein, we demonstrate the principle of light maximization by performing the gas phase reverse water gas shift (RWGS) reaction $\left(\mathrm{CO}_{2}+\mathrm{H}_{2} \rightarrow \mathrm{H}_{2} \mathrm{O}+\mathrm{CO}\right)^{11-14}$ in an annular glass cylindrical rod photoreactor ${ }^{15-17}$ with optimized uniformity and thickness of a photo-charge driven $\operatorname{In}_{2} \mathrm{O}_{3-x}(\mathrm{OH})_{y}$ nanorod coating ${ }^{18-21}$. We highlight an important advantage that has to the best of our knowledge been overlooked in similar waveguide studies, which is overcoming both the photo-current and product semisaturation limit at high photo-intensities. This improves photon-to-yield efficiencies. Further, the omni-directional optical scattering of the nanorod coatings enables light propagation due to their antennalike geometry. Along with internal reflectivity inside the photoreactor, it is possible to internally illuminate the entirety of the photo-catalyst coating. In addition to that, multiple reflection pathways of the weakly absorptive green and red wavelengths enable the band-gap trap states of the photo-catalyst to be populated ${ }^{22}$ and compel excited charge carriers from valence and conduction band edges to relax through the surface catalyst pathway rather than through bulk recombination ${ }^{23-25}$.

\section{Results}

Photo intensity trends. In this section, we compare trends in the $\mathrm{CO}$ production rate, activation energies, and photon to yield efficiencies for the coated planar and waveguide cylindrical rod geometries under batch reactor testing performed at different photo intensities and temperatures. The coating thickness of the indium oxide hydroxide $\left(\mathrm{In}_{2} \mathrm{O}_{3-x}(\mathrm{OH})_{y}\right)$ nanorod coatings on both surfaces are $5 \pm 0.3 \mu \mathrm{m}$ each. The nanorods comprise arrays of necked nanoparticles $10-20 \mathrm{~nm}$ in diameter, which enables photo-generated charges to drift within the nanorod structure and enable injection of the charges into catalytic sites. The coated waveguide (diameter of $5 \mathrm{~mm}$, length of $6 \mathrm{~cm}$ ) is encapsulated in grease-free aluminum foil (Kurt J. Lesker, UHV Al foil, \#FOILA24) along the length and back end of the waveguide to maximize side and backpropagation. Figure 1a shows that the $\mathrm{CO}$ batch reactor production rate for the coated planar substrate at $150{ }^{\circ} \mathrm{C}$ increases to $20 \mu \mathrm{mol} / \mathrm{g}$.cat.hr for corresponding photointensities ranging below $65 \mathrm{~mW} / \mathrm{cm}^{2}$, and more slowly to $27 \mu \mathrm{mol} / \mathrm{g}$.cat.hr at corresponding photo-intensities above $81 \mathrm{~mW} / \mathrm{cm}^{2}$. The diminishing rate of increase of the CO production rate is mirrored in the corresponding decrease in $\mathrm{CO}$ quantum efficiency $(0.6-0.2 \%)^{26}$, Fig. 1a inset. Conversely, the rate of increase of the $\mathrm{CO}$ production rate for the coated waveguide at $150{ }^{\circ} \mathrm{C}$ does not decrease at higher incident photo- intensities and instead presents a fairly linear rate of increase and correspondingly a relatively constant quantum efficiency $(0.6-0.7 \%)$. At $200^{\circ} \mathrm{C}$, the rates of the coated rod also increase (Supplementary Fig. 1) albeit more slowly with increasing photointensities in the same fashion as that for the coated planar substrate, however, its photon to yield efficiency is generally greater than the coated planar substrate by an additional absolute $0.25 \%$ at all values of incident photo-intensities (Supplementary Fig. 2). In general, the batch reactor rates with increasing temperatures show that the $\mathrm{Al}$ encapsulated coated waveguide cylindrical rod is more productive than the planar coated geometries at photo-intensities greater than $60 \mathrm{~mW} / \mathrm{cm}^{2}$.

The apparent activation energies at an incident photo-intensity range of $120-130 \mathrm{~mW} / \mathrm{cm}^{2}$ (determined from the averaged rates as a function of temperature) are 23.5 and $25.6 \mathrm{~kJ} / \mathrm{mol}$ for the two geometries (waveguide rod and planar, respectively) (Supplementary Fig. 3a). The difference in the activation energies between the encapsulated and un-encapsulated coated rod waveguides is fairly minor at $2.99 \mathrm{~kJ} / \mathrm{mol}$, and the $\mathrm{CO}$ yield for the aluminum encapsulated but uncoated rod waveguide is less than $2 \%$ of that of the coated rod waveguide, showing that the aluminum foil encapsulating the uncoated rod does not contribute chemically to the reaction rate. The apparent activation energies under dark conditions for the coated planar and encapsulated coated rod waveguide geometries are fairly similar at 60.0 and $62.1 \mathrm{~kJ} / \mathrm{mol}$, respectively. There is therefore a larger difference in the increase in activation energies between the dark and photo-illuminated coated planar/waveguide samples.

We now turn to gauge the performance of a flow photoreactor with a single coated $\mathrm{In}_{2} \mathrm{O}_{3-x}(\mathrm{OH})_{y}$ glass rod operating at a flow rate of $5 \mathrm{sccm}$ for $\mathrm{H}_{2}$ and $1 \mathrm{sccm}$ for $\mathrm{CO}_{2}$ (Fig. 1b). It is found that the $\mathrm{CO}$ production rate under thermal only dark conditions increases exponentially as per the Arrhenius equation to $108.3 \mu \mathrm{mol} / \mathrm{g}$.cat.hr corresponding to a temperature increase from 100 to $200{ }^{\circ} \mathrm{C}$ (Supplementary Fig. 3b). This implies a flow-reactor associated activation energy of $48.1 \mathrm{~kJ} / \mathrm{mol}$ in the dark, which decreases significantly to $23.8 \mathrm{~kJ} / \mathrm{mol}$ under a photoillumination intensity of $139 \mathrm{~mW} / \mathrm{cm}^{2}$. With increasing photointensities at the flow reactor temperature of $200{ }^{\circ} \mathrm{C}$, the $\mathrm{CO}$ rate increases significantly from 118.9 to $246.2 \mu \mathrm{mol} / \mathrm{g}$.cat.hr. The photon to yield efficiency with varying photo-intensities is more consistent than that of the coated planar substrate, with efficiencies of $0.7 \%$ at high photo-intensities and $150{ }^{\circ} \mathrm{C}$. These results show that back illumination of the catalyst coating through the internal optical reflection in a quartz waveguide, as well as the high reactant gas residence time in a flow reactor configuration, result overall in high quantum efficiencies over the photo-intensity range.

Electrical and photo-spectroscopy results. We discuss the possible rationale behind the aforementioned optical waveguide reactor performance, with photo-current measurements under varying photo-intensities and under varying reactant gas concentrations. While the obvious factor of poor photo-absorption by the subsurface may seem to account for the difference in the CO production yield of the waveguide geometry over the planar substrate, it does not fully account for the relatively stable photon to yield efficiency with increasing incident photo-intensities for the coated waveguide and a lower photon to yield efficiency for the planar substrate at high incident photo-intensities. This indicates that the distribution of the incident photo-illumination over a larger surface area due to the waveguide geometry plays a significant role in the higher $\mathrm{CO}$ production rate. As Fig. 2a shows the generated photocurrent of an $\operatorname{In}_{2} \mathrm{O}_{3-x}(\mathrm{OH})_{y}$ coated planar substrate as a function of photo-intensities rises sharply 

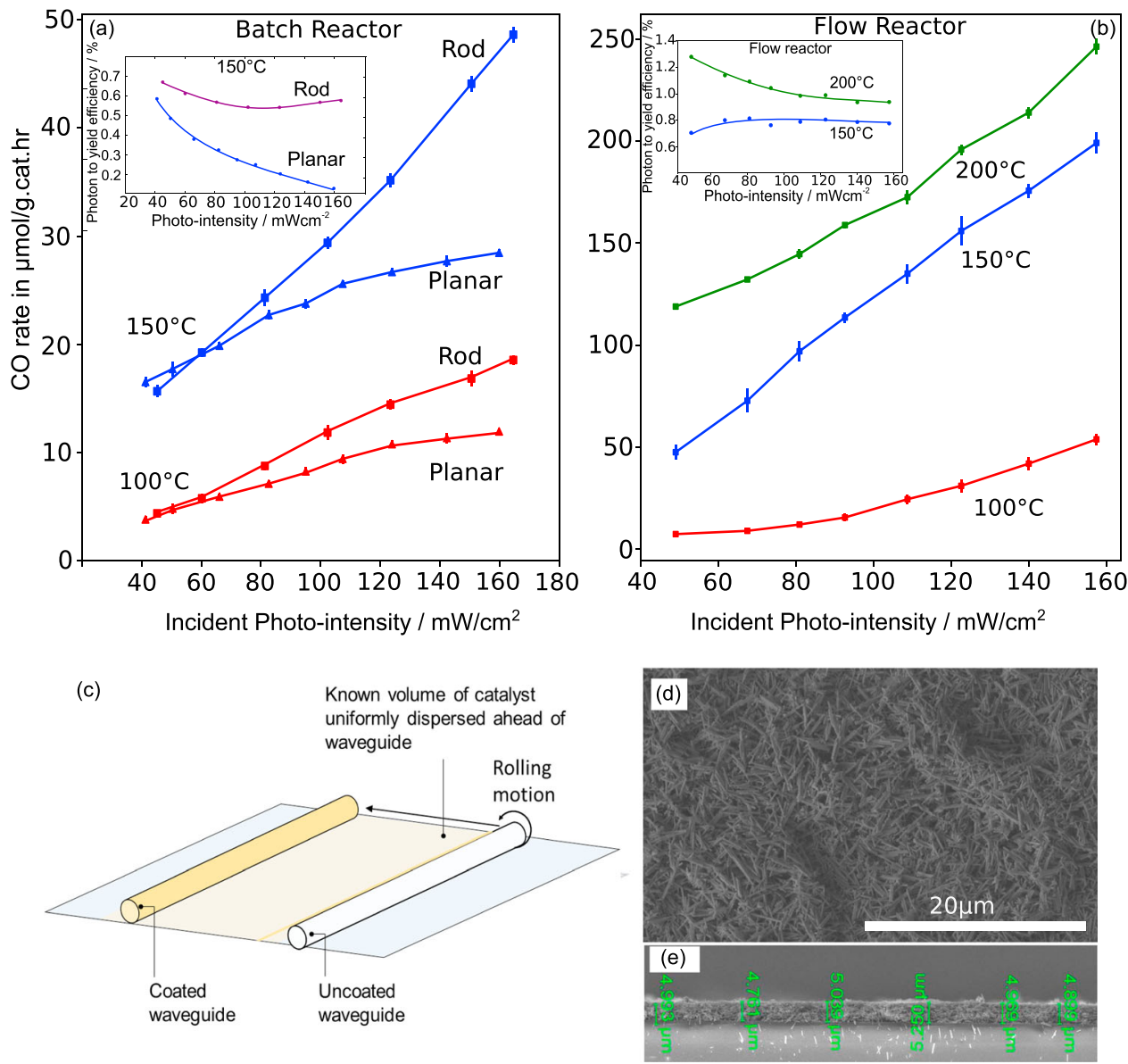

Fig. 1 Batch and flow reactor results. a, b The CO production rates and associated activation energies and photon to yield quantum efficiencies for the batch reactor and flow reactor configurations, respectively. (a) Shows the $\mathrm{CO}$ rates for the coated cylindrical rod waveguide and coated planar substrate at 100 and $150{ }^{\circ} \mathrm{C}$. The coated planar $\mathrm{CO}$ rates at $150^{\circ} \mathrm{C}$ showed semi-saturation trends at increasing photo-intensities, while the coated rod showed a linear increase. Insets of (a) shows the photon to yield efficiencies of the coated planar and rod geometries at $150^{\circ} \mathrm{C}$ batch reactor temperature with increasing photo-intensities, indicating that the coated rod waveguide has a more consistent efficiency of $0.8-0.9 \%$. $\mathbf{b}$ The CO rates for the coated rod waveguide at 100,150 , and $200^{\circ} \mathrm{C}$ flow reactor temperatures. Inset to (b) shows that the coated waveguide rods in the flow reactor have consistent photon to yield efficiencies with increasing photo-intensities. c Coating procedure of the quartz rod using a thin film colloidal solution of $\operatorname{In}_{2} \mathrm{O}_{3-x}(\mathrm{OH})_{y}$ nanorods. d, e The SEM topographic and cross-sectional view of the nanorod coating.

below $\sim 60 \mathrm{~mW} / \mathrm{cm}^{2}$ but slowly increases beyond a higher photointensity of $81 \mathrm{~mW} / \mathrm{cm}^{2}$. The photocurrent external quantum yield is approximately $5.9 \pm 0.3 \%$ within the low range of photointensities and decreases from 4.7 to $2.4 \%$ within the high range of photo-intensities.

As further evidence of the photo-intensities trend on a coated planar substrate, Fig. $2 \mathrm{~b}$ shows the in situ gas-phase electrical conductivity sensitivity plots under an increasing flow ratio of $\mathrm{CO}_{2}$ and $\mathrm{H}_{2}$ to Argon $\left(\mathrm{CO}_{2}+\mathrm{H}_{2}\right) /$ Argon. Both $\mathrm{CO}_{2}$ and $\mathrm{H}_{2}$ gases are chemisorbed onto the $\operatorname{In}_{2} \mathrm{O}_{3-x}(\mathrm{OH})_{y}$ nanorods coated surface and release free electrons to increase the measured current under an applied bias of $5 \mathrm{~V}$. The slope of the current increase with the increasing concentration of reactant gases indicates the surface chemisorption sensitivity. The electrical conductivity increases below a threshold flow ratio of 0.005 under a low photo-intensity of $26 \mathrm{~mW} / \mathrm{cm}^{2}$ and increases rapidly with increasing photointensities while the threshold value to saturation decreases to 0.023 . This indicates that the population of surface chemisorbed gas states increases with increasing photo-intensities, but its maximum sensitivity is reached at approximately $104 \mathrm{~mW} / \mathrm{cm}^{2}$ photo-intensity. The $\mathrm{H}_{2}$ component of the mixed atmosphere is more likely to be adsorbed than the $\mathrm{CO}_{2}$ component (Supplementary Figure 5) under thermal and photo-input, with the steepest increase at $150^{\circ} \mathrm{C}$ and photo-illumination under 0.002 $\mathrm{H}_{2} /$ Ar flow ratio.

The decrease in the activation energies from dark to photoillumination relates to the glovebox protected XPS reactor-based measurements (Fig. 2c, d). For a quantitative estimate of the $\mathrm{OH}$ shoulder in the O1s spectrum, we define the ratio of $\mathrm{OH}$ shoulder area in relation to the $\mathrm{O} 1 \mathrm{~s}$ spectrum corresponding to the area integral between 531 and $534.5 \mathrm{eV}$ in relation to the area for the spectral range from 528 to $534.5 \mathrm{eV}$. While a reactor temperature of $75^{\circ} \mathrm{C}$ in the dark in a $\mathrm{CO}_{2}+\mathrm{H}_{2}$ gas atmosphere does not result in significant changes to the Ols spectra in comparison with the as-prepared state, the increase in reactor temperature with a constant photo-intensity of $30.1 \mathrm{~mW} / \mathrm{cm}^{2}$ shows that the $\mathrm{OH}$ shoulder area ratio under photo-thermal conditions is larger by $190-230 \%$ than that under thermal and dark conditions, with an associated indium binding energy increase of $0.15 \pm 0.05 \mathrm{eV}$. There are two components within the changes in the $\mathrm{OH}$ shoulder: that of the peak intensity increase, and the expansion of the shoulder (Supplementary Figs. 6-8). The $\mathrm{OH}$ shoulder expansion is due to the development of $\mathrm{H}^{+} \mathrm{OH}$ sub-peak from $\mathrm{H}_{2}$ dissociation on $\mathrm{OH}$ sites, while increased peak intensity is mainly dominated by increased $\mathrm{OH}$ groups from $\mathrm{H}_{2}$ dissociation on oxide lattice sites. 

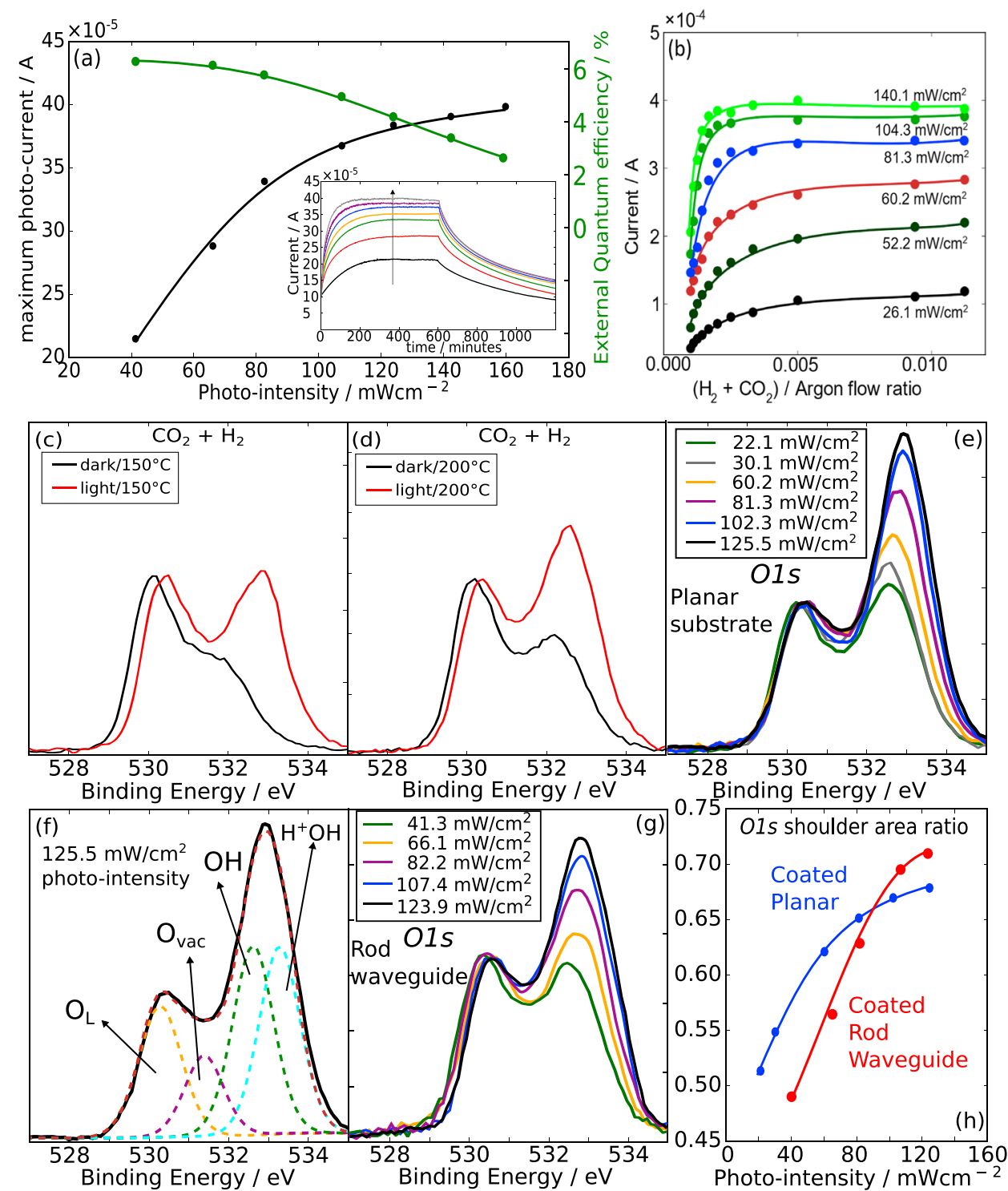

Fig. 2 Relating photo-charge and surface reactivity with photo-intensities. The photo-current trend with increasing photo-intensities; photocurrent changes with increasing flow concentration of $1 \mathrm{sccm}$ of $\mathrm{H}_{2}$ and $1 \mathrm{sccm}$ of $\mathrm{CO}_{2}$ in argon; glovebox protected XPS measurements of $\mathrm{In}_{2} \mathrm{O}_{3-x}(\mathrm{OH})_{y}$ nanorods coated on planar and cylindrical rod geometries after reactions in dark and photo-illuminated conditions at 1:1 $\mathrm{H}_{2}: \mathrm{CO}_{2}$ pressure ratio atmosphere at various temperatures. a The photocurrent trend of the coated planar substrate under increasing photo-intensities shows a sharp rise at low photo-intensities below $100 \mathrm{~mW} / \mathrm{cm}^{2}$ and semi-saturation at higher photo-intensities. b Photocurrent increase with increasing $\mathrm{H}_{2}+\mathrm{CO}_{2}$ gas concentrations and with increasing photo-intensities. $\mathbf{c}$, $\mathbf{d}$ The $\mathrm{O} 1 \mathrm{~s}$ spectra of $\ln _{2} \mathrm{O}_{3-x}(\mathrm{OH})_{y}$ nanorods on a planar surface at $150{ }^{\circ} \mathrm{C}$ and $200^{\circ} \mathrm{C}$ post dark and photo-illumination of one hour in $\mathrm{H}_{2}+\mathrm{CO}_{2}$ atmosphere (inset). The O1s spectrum of $\ln _{2} \mathrm{O}_{3-x}(\mathrm{OH})_{y}$ nanorods as prepared on a planar surface, after an hour in a vacuum. The species with FWHM widths of less than $1.3 \mathrm{eV}$ are oxide lattice, oxygen vacancy, and $\mathrm{OH}$ groups. e O1s spectra under $\mathrm{H}_{2}+\mathrm{CO}_{2}$ at $200{ }^{\circ} \mathrm{C}$ under increasing photointensities of $1 \mathrm{~h}$. The $\mathrm{OH}$ shoulder increases significantly with increasing photo-intensities. $\mathbf{f}$ The oxide species of lattice oxide, oxygen vacancies, $\mathrm{OH}$, and $\mathrm{H}^{+} \mathrm{OH}$ species are seen for the sample under the highest photo-intensity of $125.5 \mathrm{~mW} / \mathrm{cm}^{2}$. $\mathbf{g}$ The O1s spectra of the $\mathrm{In}_{2} \mathrm{O}_{3-x}(\mathrm{OH})_{y}$ nanorods coated on a rod waveguide after photo-illumination at $200{ }^{\circ} \mathrm{C}$ for $1 \mathrm{~h}$, under increasing photo-intensities. $\mathbf{h}$ The $\mathrm{O} 1 \mathrm{~s}$ shoulder ratio of the $\mathrm{In}_{2} \mathrm{O}_{3-x}(\mathrm{OH})_{y}$ rods on planar substrates and rod waveguides as a function of increasing photo-intensities.

To understand the link between photo-intensities and surface absorption of the gas reactants, we undertook XPS measurements of the coated waveguide and coated planar substrate post various photo-intensities and reactant atmospheres. The O1s spectra (Fig. 2e, g) show that with increasing incident photo-intensities the $\mathrm{OH}$ shoulder grows with intensities on both planar and waveguide substrates. With increasing photo-intensities there is also a small binding energy increase of $0.1-0.2 \mathrm{eV}$ in the $\mathrm{O}_{\mathrm{L}}$ lattice sub-peak and more significantly with $\sim 0.3 \mathrm{eV}$ in the $\mathrm{OH}$ shoulder peak, indicating that a greater fraction of $\mathrm{H}_{2}$ dissociation occurs on the $\mathrm{OH}$ group than on the oxygen lattice sites.
The quantitative growth of the $\mathrm{OH}$ shoulder with increasing photo-intensities was compared between the planar coated and waveguide coated geometries (Fig. 2h). The $\mathrm{OH}$ shoulder growth on the coated planar substrate is fairly linear at low to mid-photointensities but increases more slowly beyond $66 \mathrm{~mW} / \mathrm{cm}^{2}$, which correlates approximately with the photo-current trend. For the coated rod waveguide, the $\mathrm{OH}$ shoulder area ratio of $\sim 0.63$ under an incident lamp photo-intensity of $82.6 \mathrm{~mW} / \mathrm{cm}^{2}$ is equivalent to that of the coated planar substrate under an incident lamp photointensity of $60.2 \mathrm{~mW} / \mathrm{cm}^{2}$. However, above an incident photointensity of $\sim 95 \mathrm{~mW} / \mathrm{cm}^{2}$, the $\mathrm{OH}$ shoulder ratio growth for the 
coated rod waveguide is more linear than the coated planar substrate. This is likely due to the effective lower photo-intensity exposed to the coating on the rod waveguide. Since the photonexcited-electron yield and photo-induced increase in $\mathrm{OH}$ species are more efficient at lower photo-intensities than higher photointensities, a greater mass of catalyst coated on a quartz rod waveguide can be illuminated with a photo-intensity that enables high photon to $\mathrm{CO}$ yield efficiencies. This results in an overall CO product rate improvement when the yield is normalized over the mass of the catalyst.

Overall, these results highlight the link between photogenerated charge carriers in the $\operatorname{In}_{2} \mathrm{O}_{3-x}(\mathrm{OH})_{y}$ system and its effect on enhancing reactivity in the RWGS reaction. Indeed, the $\mathrm{OH}$ shoulder growth of the coated rod at the maximum photoillumination is $294 \%$ greater than the $\mathrm{OH}$ growth associated with dark thermal conditions. In this context, photo-excited charge carriers significantly enhance the $\mathrm{CO}$ conversion rate, where photo-excited carrier hopping lifetime measurements being correlated with higher $\mathrm{CO}$ rates ${ }^{21}$. As well, reaction rate kinetic rate studies showed that photo-illumination increases the order of reaction of the $\mathrm{H}_{2}$ partial pressure from 0 to $1 / 3$. Furthermore, transient absorption pump-probe spectroscopy showed that the fraction of the probe signal associated with long-lived excited states at the pump wavelength of $405 \mathrm{~nm}$ extends to $0.4-0.45$ at a very low laser fluence of $0.20 \mathrm{~mJ} / \mathrm{cm}^{2}$, but drops ${ }^{27}$ to 0.02 at a higher fluence of $1.33 \mathrm{~mJ} / \mathrm{cm}^{2}$. This shows that long-lived charge states are more prevalent at low photo-intensities. The effect of low-intensity photo-illumination is to excite charge carriers on the surface that destabilizes charge neutrality and require charge carrier recombination through chemical adsorption of suitable reactant(s). The energetically shallow hole- capturing $\mathrm{OH}$ group and shallow electron-capturing unsaturated indium site generates a spatially separated charge pair that induces a polar electrical field across the SFLP site. Subsequently, by induction negatively charged $\mathrm{In}-\mathrm{H}^{-}$and positively charged $\mathrm{H}^{+} \mathrm{OH}$ groups are created through $\mathrm{H}_{2}$ heterolytic dissociation ${ }^{28}$. Because the presence of $\mathrm{H}^{+} \mathrm{OH}$ generates new mid-gap defect states within the bandgap, the subsequent adsorption of a $\mathrm{CO}_{2}$ molecule at the indium hydride and protonated hydroxyl group generates an intermediate that enables carrier recombination to take place therein. The intermediate state subsequently dissociates to $\mathrm{CO}$ and $\mathrm{H}_{2} \mathrm{O}$. Hence, reinstatement of surface charge neutrality occurs through the adsorption of two reactants to form a new surface recombination center that acts as a separate recombination pathway other than the straightforward recombination pathway through the bulk.

Optical scattering and waveguiding. One unique aspect of our $\mathrm{In}_{2} \mathrm{O}_{3-x}(\mathrm{OH})_{y}$ coated rod waveguide photoreactor is its waveguide behavior for non-absorptive and weakly absorptive wavelengths. Despite the porosity of the coating, red $(732 \mathrm{~nm})$ and green $(535 \mathrm{~nm})$ laser light at an incident angle of $60^{\circ} \mathrm{can}$ indeed propagate and internally reflect through the coated optical rod and transmit through to the other end (Fig. 3a-c). With blue laser illumination, the intensity decreases with the length of the rod, showing that the coating is partly absorbing blue light as it is internally reflected within the quartz rod. To distinguish the amount of light being transmitted through the rod or light reflected from the cylinder surface, we carried out an integrating sphere measurement of diffused transmittance (Fig. 3d) of coated/ uncoated rods encapsulated and unencapsulated at the back end with reflective aluminum foil. The cap eliminates the transmittance of the spectrometer beam through a direct optical path and reflected optical paths, revealing the transmittance of the leakage through the sides of the cylindrical surface. Figure $3 \mathrm{e}$ shows that the catalyst coating itself has $\sim 30-37 \%$ optical leakage for wavelengths greater than $500 \mathrm{~nm}$. The direct transmittance through the end of the rod is $40-45 \%$ of the incident light. In contrast, the uncoated quartz rod is effective as a waveguide yielding nearly $90 \%$ transmittance, accounted for by the sum of the optical leakage through the sides and through the end of the rod. However, with the cap on the rod end the optical leakage of $>500$ $\mathrm{nm}$ light through the sides of the rod drops significantly to $18-27 \%$. The optical leakage of the $\operatorname{In}_{2} \mathrm{O}_{3-x}(\mathrm{OH})_{y}$ coated rod is thus comparable with that of the rod with no coating, hence the
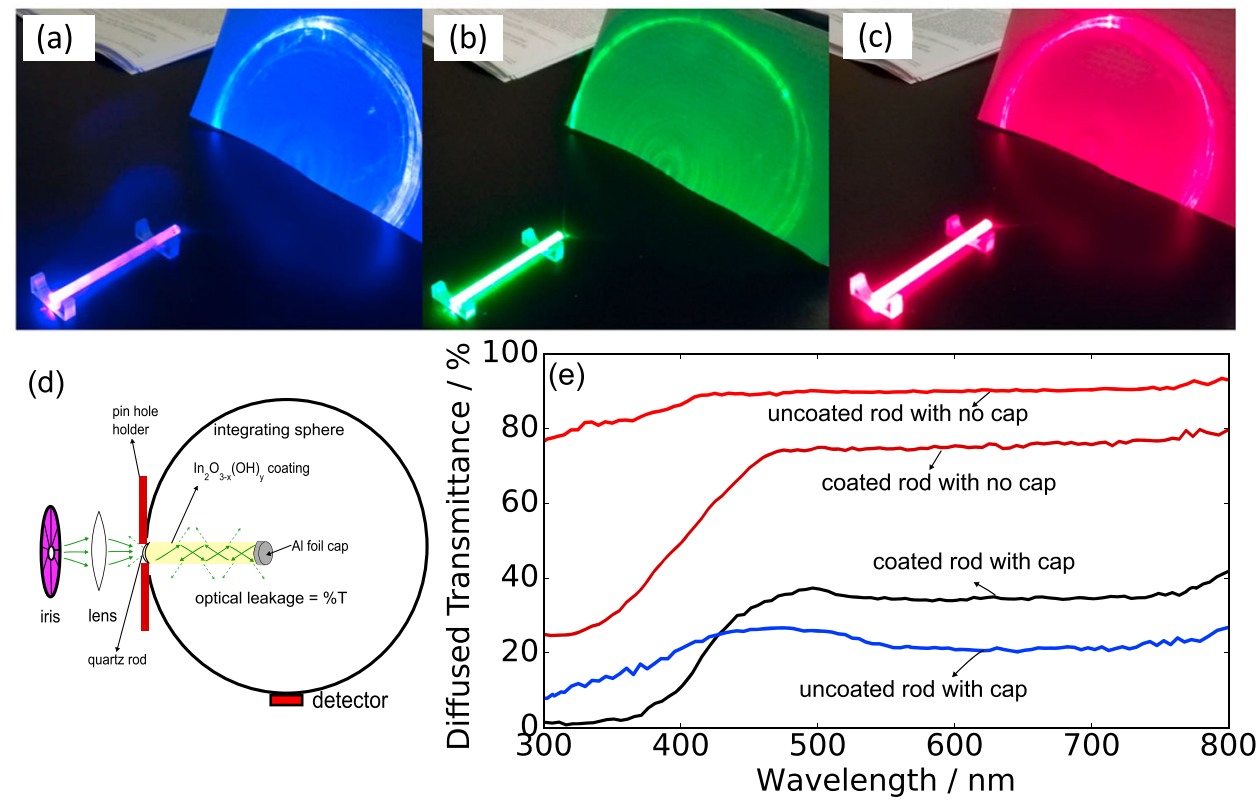

Fig. 3 Spectral waveguiding. Waveguiding of blue (a), green (b), and red (c) laser illumination at an angle of incidence of $60^{\circ}$. d The integrating sphere measurement of the optical leakage through an $\ln _{2} \mathrm{O}_{3-x}(\mathrm{OH})_{y}$ coated cylindrical quartz rod waveguide, with e showing the optical leakage spectra through the sides (along the length) of a coated and uncoated cylindrical rod waveguide. 

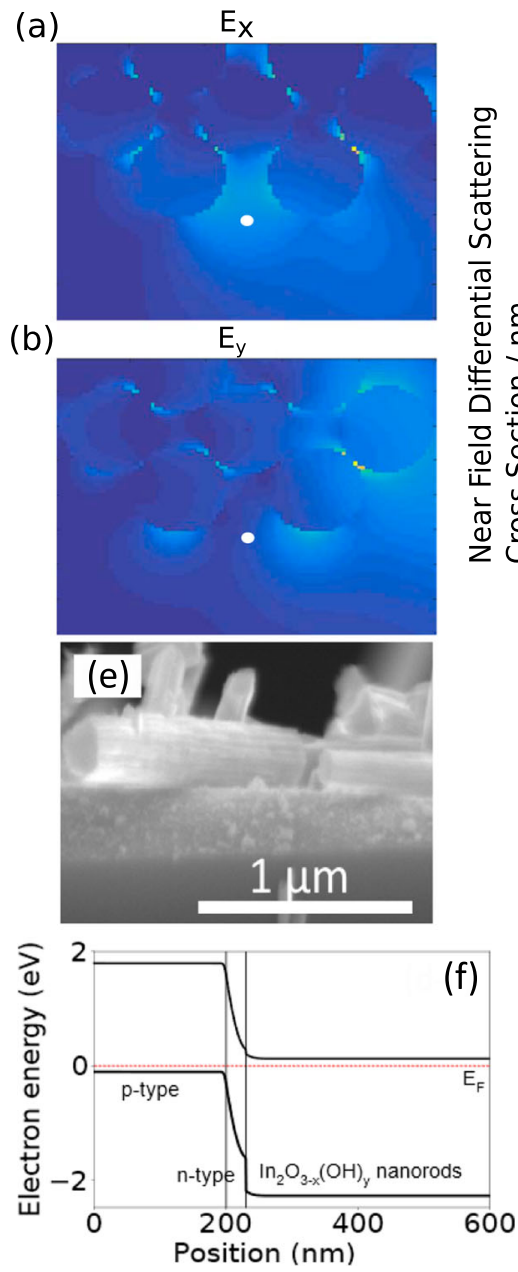
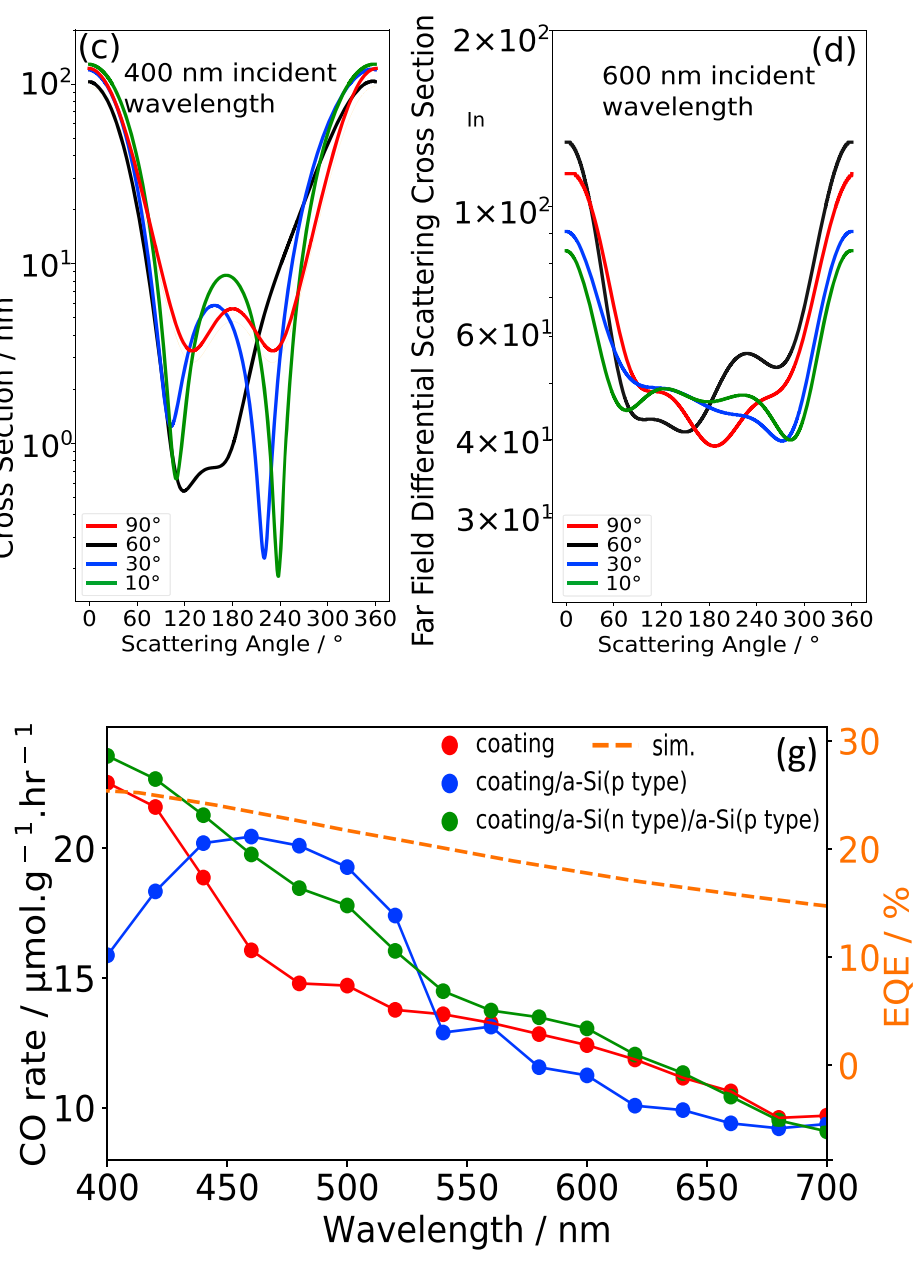

Fig. 4 Nanorod optical scattering. a, b The optical Mie scattering simulations of an array of cylindrical rods with refractive index of indium oxide at 400 and $500 \mathrm{~nm}$ incident wavelength. The array of cylindrical rods of $60 \mathrm{~nm}$ diameters near the scatterer point is shown, as marked by the white dot, under a plane wave at an incident angle of $30^{\circ}$ to the $x$-axis. The scattering intensity plots under the $\mathbf{a} E_{x}$ and $E_{y} \mathbf{b}$ components of the incident plane wave are shown, respectively. c, d The near field and far-field scattering cross-sections at a range of scattering angles under several incident angles from $90^{\circ}$ to $10^{\circ}$ from the positive $x$-axis plane with 400 and $600 \mathrm{~nm}$ wavelengths, respectively. e SEM cross-sectional images of nanorods on $200 \mathrm{~nm}$ p-type/40 nm ntype silicon layers. The white scale bar represents $1 \mu \mathrm{m}$ length. $\mathbf{f}$ Calculated equilibrium band diagram of $p$-type a-Si/n type a-Si/In ${ }_{2} \mathrm{O}_{3-x}(\mathrm{OH})_{y}$ system. g Photo-action spectroscopy of quartz rod coated with $\ln _{2} \mathrm{O}_{3-x}(\mathrm{OH})_{y}$ nanorods (red), nanorods on $p$-type amorphous silicon (blue), and nanorods on $n$ type/p-type amorphous silicon (green). The nanorods on $p$-type silicon have increased CO rates in the green regime, while nanorods on $n$-type $\mathrm{Si} / p$-type $\mathrm{Si}$ have a broader increase in $\mathrm{CO}$ rates across the blue-green regime. The simulated EQE of an $n$-type $\mathrm{Si} / p$-type Si/indium-oxide stack is shown in orange.

$\mathrm{In}_{2} \mathrm{O}_{3-x}(\mathrm{OH})_{y}$ coating acts as a fairly effective waveguide in green and red wavelength regimes.

To determine if the nanorod geometry contributes optically to the propagation of light through the waveguide, the scattering behavior for the indium oxide hydroxide nanorod geometry was determined as a function of different incident angles, near the bandgap absorption wavelength of $400 \mathrm{~nm}$ for indium oxide hydroxide. Based on trends in optical scattering cross sections for an array of cylindrical rods (Fig. 4a) and given the refractive index of indium oxide, the rods exhibit high scattering at shallow incident angles of an incoming plane wave in the near and farfield (e.g., a near field scattering angle between $110^{\circ}$ and $230^{\circ}$ at an incident angle of $30^{\circ}$ ). For incident radiation at a wavelength of $600 \mathrm{~nm}$ and at $30^{\circ}$ angle and other angles, the scattering crosssection width of $4-4.9 \mathrm{~nm}$ is fairly broad at all scattering angles, highlighting that scattering of these nanorods is fairly independent of incident angles at $600 \mathrm{~nm}$ wavelength. Since the nanorods have inherently greater scattering than spheres with the same diameter of $60 \mathrm{~nm}$, by at least 1 order of magnitude in the far-field (Supplementary Fig. 11), hence the $\operatorname{In}_{2} \mathrm{O}_{3-x}(\mathrm{OH})_{y}$ nanorods (Supplementary Fig. 12) scatter light effectively within the waveguide given that light leakage can be minimized by the reflective foil. Indeed, the optical path lengths within a rough film can be increased by a factor of $4 n^{2} / \sin (2 \theta)$, which is the wellknown Lambertian limit, where $n$ is the refractive index of the scattering film, and $\theta$ is the acceptance angle at which the light ray is incident onto the scattering film. The absorbance of the film is then $A(\lambda)=1-e^{-4 n^{2} \alpha(\lambda) d}$ where $\alpha(\lambda)$ is the absorption coefficient dispersion $\left(\alpha(600 \mathrm{~nm})=277 \mathrm{~cm}^{-1}\right)$ and $\mathrm{d}$ the film thickness, assuming no reflectance. Hence, at the wavelength of 600 $\mathrm{nm}$, the absorbance of the catalytic film increases from 0.13 to a maximum of 0.76 for a thickness of $5 \mu \mathrm{m}$ at the Lambertian limit.

We can exploit this visible wavelength scattering behavior in the quartz rod waveguide since $\operatorname{In}_{2} \mathrm{O}_{3-x}(\mathrm{OH})_{y}$ has a weak and long optical absorption tail extending from the absorption edge of 470-680 nm (Supplementary Fig. 13), which is attributed to Urbach tail states (associated with the aforementioned $\mathrm{OH}, \mathrm{O}_{\mathrm{vac}}$ defects) of lower energies within the bandgap. Further evidence of 
the extended band gap states was shown in the UPS measurements (Supplementary Figs. 6e and 7e). The valence band edge showed an absorption tail extending below $2 \mathrm{eV}$ after photoillumination in the reactant gas atmosphere. Hence, with a UV bandpass filter that absorbs wavelengths smaller than $410 \mathrm{~nm}$, the $\mathrm{CO}$ rate for a coated planar substrate is $7.75 \pm 0.32 \mu \mathrm{mol} / \mathrm{g}$.cat.hr, but is higher by a factor of $4.6(35.6 \pm 0.21 \mu \mathrm{mol} / \mathrm{g}$.cat.hr $)$ for the encapsulated coated rod waveguide. With a yellow filter and a red filter that block out wavelengths smaller than 500 and $620 \mathrm{~nm}$, respectively, the $\mathrm{CO}$ rates for the coated planar substrate are fairly small at $0.6-1.02 \pm 0.2 \mu \mathrm{mol} / \mathrm{g}$.cat.hr, but are higher by a factor of $8.7(9.68 \pm 0.52 \mu \mathrm{mol} /$ g.cat.hr) and $8.1(4.87 \pm 0.34 \mu \mathrm{mol} /$ g.cat.hr $)$ for the coated rod waveguide, respectively, which together show that the optical absorption tail extends even beyond the yellow wavelength regime. These results show that the longer optical path lengths of the weakly absorptive wavelengths can be utilized to enhance $\mathrm{CO}$ production at sub-bandgap photon energies. In addition, future development of such rod waveguide photoreactors can include other photocatalysts absorbing in different wavelength regimes in order to create a "tandem" waveguide that allows the entire illumination spectrum to be harvested by $\mathrm{In}_{2} \mathrm{O}_{3-x}(\mathrm{OH})_{y}$ and other photo-catalytic systems.

As an example of harvesting the visible wavelength regime by pairing $\operatorname{In}_{2} \mathrm{O}_{3-x}(\mathrm{OH})_{y}$ with another material on a quartz rod, we coated the quartz rod waveguide with doped amorphous silicon via plasma-enhanced chemical vapor deposition. The $\mathrm{In}_{2} \mathrm{O}_{3-x}(\mathrm{OH})_{y}$ nanorods are subsequently applied onto the silicon film and the waveguide encapsulated with $\mathrm{Al}$ foil. The $\mathrm{CO}$ rates for the $200 \mathrm{~nm} \mathrm{p}+$ doped silicon/ $/ \mathrm{In}_{2} \mathrm{O}_{3-x}(\mathrm{OH})_{y}$ system in the batch reactor are $4.31 \pm 0.35 \mu \mathrm{mol} / \mathrm{g} . c a t . h r$ and $12.54 \pm 0.33 \mu \mathrm{mol} /$ g.cat.hr under the red and yellow filters, respectively, thus showing a significant increase in conversion rates in the visible wavelength regime-specifically, by a factor of 1.28. Photo-action spectroscopy of $\mathrm{CO}$ yield as a function of wavelength shows that the $p+\mathrm{Si} / \mathrm{In}_{2} \mathrm{O}_{3-x}(\mathrm{OH})_{y}$ system produces significantly greater $\mathrm{CO}$ at wavelengths from 440 to $520 \mathrm{~nm}$, specifically an increase of $19 \%$ over the coated quartz rod waveguide. The increase in the visible regime harvesting can be associated with the diode junction created between the $\mathrm{p}+$ doped silicon and intrinsically n-type $\operatorname{In}_{2} \mathrm{O}_{3-x}(\mathrm{OH})_{y}$ junction, which drives electrons from the silicon junction into the $\operatorname{In}_{2} \mathrm{O}_{3-x}(\mathrm{OH})_{y}$ layer. Simulated EQE spectrum $^{29}$ of the $\mathrm{p}-\mathrm{n}$ junction showed a broad charge carrier generation across the visible spectrum, hence, in order to improve charge carrier separation (Fig. 4e, f), a thin n-doped silicon layer of $40 \mathrm{~nm}$ thickness was deposited on the $p+$ layer before coating $\mathrm{In}_{2} \mathrm{O}_{3-x}(\mathrm{OH})_{y}$ nanorods. The $p+\mathrm{Si} / n \mathrm{Si} / \mathrm{In}_{2} \mathrm{O}_{3-x}(\mathrm{OH})_{y}$ showed a greater $\mathrm{CO}$ rate with increasing photo-intensities than the $p+\mathrm{Si}$ / $\mathrm{In}_{2} \mathrm{O}_{3-x}(\mathrm{OH})_{y}$ coated waveguide (Supplementary Figure 14). In addition, the resulting photo-action spectroscopy (Fig. $3 \mathrm{~g}$ ) of the $p+\mathrm{Si} / n \mathrm{Si} / \mathrm{In}_{2} \mathrm{O}_{3-x}(\mathrm{OH})_{y}$ layer, showed increased production across the wavelength range of $400-560 \mathrm{~nm}$, resulting in an overall UV to visible regime increase of $27 \%$ over the nanorod coated waveguide.

Persistent photocatalysis. An intrinsic material advantage of using $\mathrm{In}_{2} \mathrm{O}_{3-x}(\mathrm{OH})_{y}$ nanorod coatings is its persistent photoconductivity effect ${ }^{30,31}$, as shown earlier in Fig. $2 \mathrm{a}$-inset, which showed that photo-current values saturate within $2 \mathrm{~h}$ of photoillumination but slowly decays to its original dark current value in $7 \mathrm{~h}$ or more. Indeed, electron paramagnetic resonance (EPR) spectra (Fig. 5a) of the nanorods under $405 \mathrm{~nm}$ laser illumination exhibit a rapid increase in signal intensity within $15 \mathrm{~min}$, followed by a gradual decrease in signal intensity post illumination (Fig. 5b, c). The EPR signal of indium oxide is commonly associated with singly ionized oxygen vacancy defects ${ }^{32,33}$, which implies the photo-ionization of neutral oxygen vacancies, with trapped electrons that are slowly released postillumination.

Figure $5 \mathrm{~d}$ shows the results of regular and persistent $\mathrm{CO}$ production rate during and post photo-illumination respectively, where the time-accumulated $\mathrm{CO}$ product yield of the aluminum foil encapsulated $\operatorname{In}_{2} \mathrm{O}_{3-x}(\mathrm{OH})_{y}$ coated rod waveguide increases from 0.7 to $114.6 \mathrm{ppm}$ within $3 \mathrm{~h}$ of $107 \mathrm{~mW} / \mathrm{cm}^{2}$ photoillumination at $200^{\circ} \mathrm{C}$. The $\mathrm{CO}$ production average rate is $\sim 38$ $\mathrm{ppm} / \mathrm{h}$, yet increases at a comparable averaged rate of $23.4 \mathrm{ppm} / \mathrm{h}$ after turning off photo-illumination for a period of $2 \mathrm{~h}$. Subsequently, the rate increase is smaller and linear at 11.9 $\mathrm{ppm} / \mathrm{h}$. By comparison, the thermal only reactor condition of $200{ }^{\circ} \mathrm{C}$ under dark showed a linear averaged CO product yield increase of $14.1 \mathrm{ppm} / \mathrm{h}$, which is in line with the yield increase rate post $3 \mathrm{~h}$ after turning off photo-illumination. The averaged $\mathrm{CO}$ rate is thus enhanced by a factor of 1.62 over the averaged thermal rate within the persistent period. In the flow reactor configuration, the coated waveguide rod exhibits a $\mathrm{CO}$ decay period of $35-45 \mathrm{~min}$ at a reactor temperature of $120^{\circ} \mathrm{C}$ (Fig. $5 \mathrm{e}$ ), and $50-55 \mathrm{~min}$ at a reactor temperature of $90^{\circ} \mathrm{C}$ (Fig. 5f). The averaged $\mathrm{CO}$ yield over the decay period is greater than the average thermal only yield by a factor of 1.44 and 1.57 for 90 and $120^{\circ} \mathrm{C}$, respectively. Since the photo-thermal associated temperature of $\operatorname{In}_{2} \mathrm{O}_{3-x}(\mathrm{OH})_{y}$ was determined to be less than $20^{\circ} \mathrm{C}$ under 0.8 sun illumination, it is unlikely that the persistent photocatalysis is due to residual thermal effects after turning off photoillumination.

Assuming a time-dependent exponential behavior, the rate of decay has an exponential decay constant of 5.10 and $1.73 \mathrm{~min}$, respectively. However, the fit is not accurate with the experimental decay profile, indicating a sublinear decay trend which is indicative of a continuum of band defects with a range of trap energies $^{34}$, since a single trap energy level results in an exponential decay trend in photocurrent after turning off photo-illumination. With a continuum of trap states that are distributed close to each other in energy and spatially proximal, successive hopping of trapped electrons can re-emit electrons back into the conduction band, resulting in a persistent population of excited charge carriers after photo-illumination (Fig. 6a). Due to the population of excited charge carriers, charge injection into a surface $\mathrm{OH}$ group, as well as the coordinately unsaturated indium site (Supplementary Fig. 17), can induce heterolytic dissociation of the $\mathrm{H}_{2}$ molecule (as described earlier) which subsequently reacts with $\mathrm{CO}_{2}$ through the $\mathrm{H}^{+} \mathrm{OH}$ indium terminated and $\mathrm{H}^{-}$indium terminated species to form $\mathrm{CO}$ and $\mathrm{H}_{2} \mathrm{O}$ products of the RWGS reaction (Fig. 6b).

Overall, the $\operatorname{In}_{2} \mathrm{O}_{3-x}(\mathrm{OH})_{y}$ waveguide photoreactor is suitable as an integrated solar concentrator batch reactor (Fig. 6c) with no external heating, where the $\mathrm{CO}$ rate can remain relatively high even after sunset or during cloudy periods in the day. As an example, we operated a solar batch concentrator (without solar tracking) during daylight hours and then continued to monitor the CO yield in the night post-sunset. As shown in Fig. 6d, through the course of the night the CO yield increased by $19 \%$ $(24.05 \pm 0.22 \mathrm{ppm})$-over and above that measured at the conclusion of the sunlit hours (some $9 \mathrm{~h}$ of solar illumination yielding $20.45 \pm 0.43 \mathrm{ppm}$; the rate of $8.89 \pm 0.25 \mu \mathrm{mol} / \mathrm{g}$.cat.hr).

The ability to slowly release charge carriers from trap defect states for further chemical reactions occurs for an all-organic poly-heptazine imide ${ }^{35}$. Herein it is established that an allinorganic defect-laden $\mathrm{In}_{2} \mathrm{O}_{3-x}(\mathrm{OH})_{y}$ photocatalyst can prolong solar fuel generation and overcome the "duck curve" issue associated with on-demand energy utilization during low solar illumination in the evenings, a step-towards solving the intermittency problem for future solar fuels farms. 

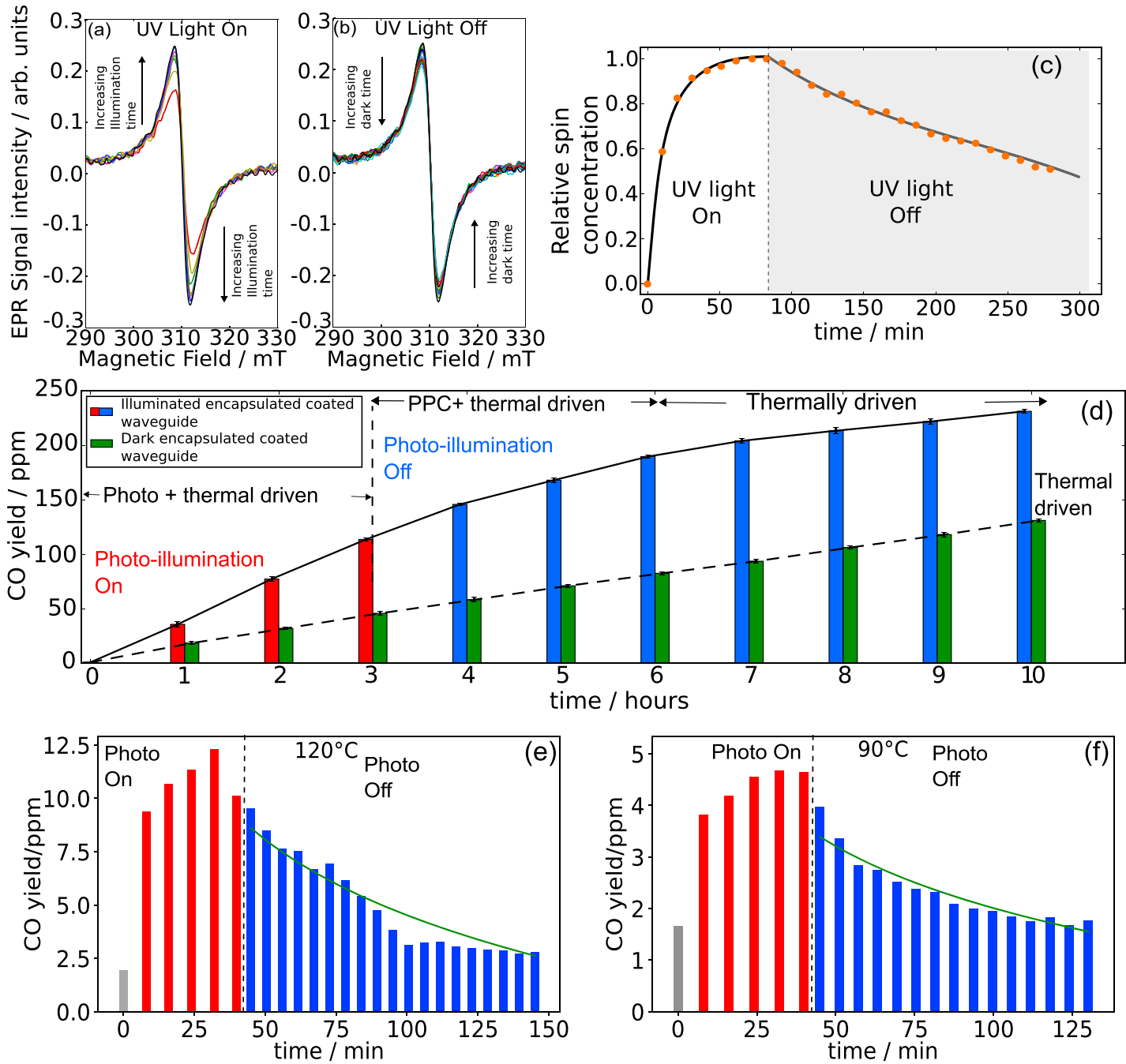

Fig. 5 Persistent photo-catalysis. EPR spectra of $\mathrm{In}_{2} \mathrm{O}_{3-x}(\mathrm{OH})_{y}$ nanorods under UV illumination (a) and post illumination (b) with time intervals of 5 min. c The change in spin concentrations normalized over the maximum spin concentration. $\mathbf{d}$ The $\mathrm{CO}$ yield with time for an aluminum foil encapsulated $\mathrm{In}_{2} \mathrm{O}_{3-x}(\mathrm{OH})_{y}$ coated waveguide in batch reactor configuration, under photo-illumination for $3 \mathrm{~h}$ and post photo-illumination, under $200^{\circ} \mathrm{C}$ reactor temperature. Persistent photoconductivity (PPC) enables a comparable yield to increase immediately after photo-illumination, which is greater than that of the dark condition under the same reactor temperature. e, $\mathbf{f}$ The $\mathrm{CO}$ yield decay after post-illumination in flow reactor configuration, at reactor temperatures of $\mathbf{e} 120^{\circ} \mathrm{C}$ and $\mathbf{f} 90^{\circ} \mathrm{C}$. The regression fitted exponential decay trends are shown in green lines.

\section{Discussion}

In this study, we show that the principle of light concentration yields diminishing returns on product yield, whereas applying a principle of light maximization enables significantly higher photon-to-yield efficiencies and higher catalysis rates. High effciencies and high rates are not possible under straightforward light concentration due to the volumetric generation of charge carriers over-saturating the surface density of catalytic active sites, as well as charge carrier recombination rates increasing with increasing photo-intensities. When applied on a simple cylindrical quartz rod waveguide, defect laden $\operatorname{In}_{2} \mathrm{O}_{3-x}(\mathrm{OH})_{y}$ serves as a suitable photocatalyst for the RWGS reaction at mild reactor temperature. In particular, we show markedly improved performance owing to several factors pertaining to opticalphotocatalytic synergy. The photo-current and XPS derived $\mathrm{OH}$ species spectra showed that on the coated waveguide, the photogenerated surface electron concentration efficiently maximizes the activation of surface catalytic sites. Further, the optimization of the nanorod geometries enables wide-angle scattering for efficient light propagation through the waveguide, which enables a large area of catalyst material to be illuminated with optimal light intensities. The propagation and internal reflection of green and red wavelengths enable sub-gap trap states to be occupied continuously, which can enable conduction band electrons and valence band holes to recombine through the surface catalytic pathway. The presence of sub-gap trap states can be further exploited through the phenomenon of persistent photoconductivity.

Future development of photocatalyst-coated waveguides should take advantage of the ability to maximize photocatalytic performance over a large surface to volume ratio. In addition, tandem photocatalytic layers can be laterally coated so different sections of the waveguide can utilize various regimes of the wavelength spectrum. To maximize catalyst loading and catalystgas contact, several coated tandem waveguides integrated into a compact photo-reactor configuration (e.g., shell and tube), in which space minimization between waveguides, can potentially allow any transmitted refracted light from one coated layer to be used by another coated layer. As presented in this work, compact photoreactor configurations integrated with solar concentrators, result in both higher quantum efficiencies and spectral utilization. Moreover, due to the improved $\mathrm{CO}$ production rate from 
(a)

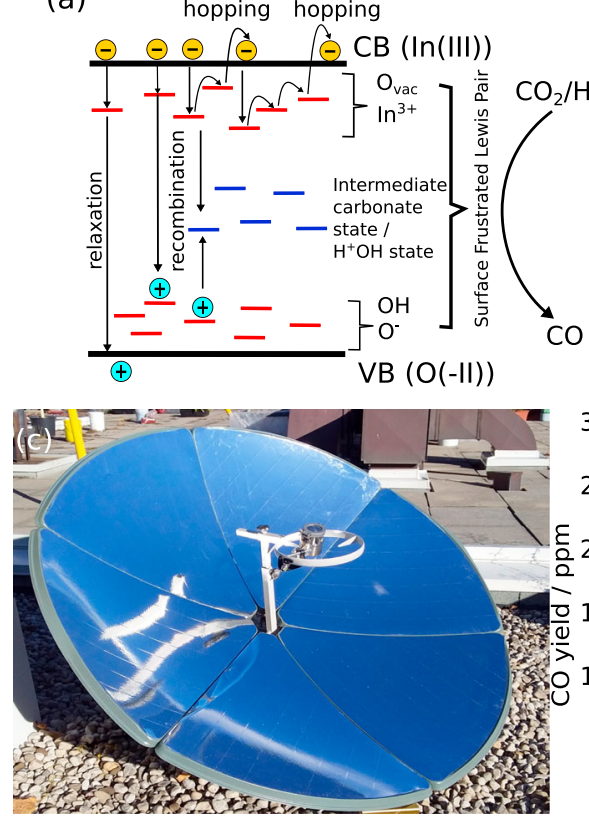

(b)

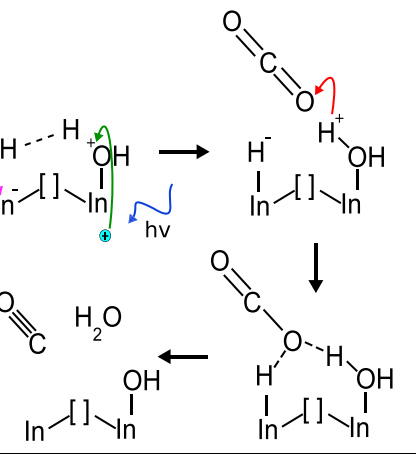

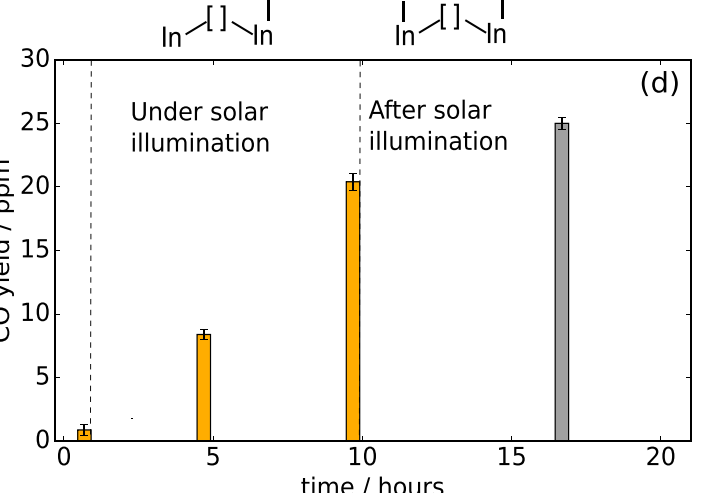

Fig. 6 Outfield test. a An illustration of a band diagram where the various defect states populate the bandgap as shallow and deep energy traps. A photo-excited electron carrier can decay through recombination or relaxation, or be trapped in shallow states and undergo hopping which can lead to re-emission into the conduction band edge. Each hopping step into a neighboring trap requires a time interval, resulting in a persistent population of excited carriers after photo-illumination is off. $\mathbf{b}$ The reaction mechanism of an SFLP site consisting of an indium, oxygen vacancy, and hydroxyl group site. Photo-excited charge carriers within the bulk are injected into surface $\mathrm{OH}$ groups, followed by heterolytic splitting of an incident $\mathrm{H}_{2}$ molecule into a proton and hydride. Subsequent formation of a carbonate dissociates oxygen from the carbon dioxide to form $\mathrm{CO}$ and $\mathrm{H}_{2} \mathrm{O}$. c The rooftop solar concentrator and reactor attached to it. $\mathbf{d}$ The $\mathrm{CO}$ yield of the encapsulated coated rod waveguide after $9 \mathrm{~h}$ of solar illumination and postillumination.

waveguide support, the intrinsic property of persistent photocatalysis in $\operatorname{In}_{2} \mathrm{O}_{3-x}(\mathrm{OH})_{y}$ can be exploited to enable solar fuel production after sunset.

\section{Methods}

Reactor measurements. For flow reactor measurements, a flow rate of $5 \mathrm{sccm} \mathrm{H}$ and $1 \mathrm{sccm} \mathrm{CO} \mathrm{CO}_{2}$ was used at 14.1 psi with custom-built flow controllers. The flow reactor comprises a flange with a glass viewport, with a side gas connection on the flange for the input flow, and a tube connected to the bottom of the flange enables the aluminum foil encapsulated coated waveguide rod to be squeezed into the tube, such that the front of the waveguide rod is exposed to the glass viewport only. A thermocouple at the back end of the tube would be in contact with the surface of the coating on the back end of the waveguide rod. For persistent $\mathrm{CO}$ yield measurements, the reactor would be under high temperature and gas flow for at least $3-4 \mathrm{~h}$ so that thermal equilibrium is established before turning on photoillumination.

For batch reactor measurements, the reactor would be vacuum pumped to a pressure of $2 \times 10^{-2}$ mbar under the set reactor temperature and under the lowest intensity photo-illumination, followed by $\mathrm{H}_{2}$ introduction to a pressure of 26-28 psi, for a period of $5 \mathrm{~min}$, before the introduction of $\mathrm{CO}_{2}$ to a pressure of $48-52 \mathrm{psi}$. The time at which the $\mathrm{CO}_{2}$ is introduced is considered the start of the reaction cycle. The reactor would be under temperature and photo-illumination for an hour before GC measurement. At least three subsequent data points would be collected at every hour, in order to generate the uncertainty range. The photointensity would be increased with an interval step of $15-20 \mathrm{~mW} / \mathrm{cm}^{2}$, and the reactor reset to vacuum state for the next set of measurements as discussed above. The aluminum foil encapsulated coated waveguide rod would be set in the center of the reactor by affixing the rod partly through a center hole in the cap of the reactor backend.

Electrical measurements. For the electrical conductivity-gas sensitivity measurement, a modified cryostat was used to hold the sample with 4 probe needles on a set of square gold electrodes $0.5 \mathrm{~mm}$ distance apart in a square configuration. For each temperature and photo-intensity measurement, a separate set of $0.5 \mathrm{mg}$ powder would be used. The cryostat would be pumped to $\sim 1 \times 10^{-2}$ mbar before introducing a $1000 \mathrm{sccm}$ flow of Ar and $1 \mathrm{sccm}$ flow of $\mathrm{H}_{2}$ and $1 \mathrm{sccm}$ flow of $\mathrm{CO}_{2}$. The argon flow would be varied using a custom potentiostat to reduce the flow of
Argon while maintaining the same flow rates for $\mathrm{H}_{2}$ and $\mathrm{CO}_{2}$. Two hours of photoillumination at the set temperature would take place under vacuum, before carrying out the electrical conductivity-gas sensitivity measurements.

Silicon deposition. PECVD a-Si:H Deposition parameters before coating with indium oxide nanorods: The quartz rods were cleaned using Acetone, Methanol, and DI Water. The quartz rods were immersed in each solvent in an ultrasonic cleaner for $15 \mathrm{~min}$, then were additionally rinsed with DI water and blown dry with nitrogen. For the deposition of a-Si:H, an RF PECVD chamber on an MVS Systems cluster tool was used. For each doped layer, there were two depositions in total, one on the cylindrical surface directly exposed to the chamber, followed by a rotation to expose the other half-side of the cylindrical surface. The sample deposition parameters are as follows. The p-doped a-Si:H and n-doped a-Si:H, respectively, has electrode spacing $34 \mathrm{~mm}$ each, temperature 160 and $180{ }^{\circ} \mathrm{C}, \mathrm{SiH}_{4}$ flow rate of $8 \mathrm{sccm}$ each, the pressure of 0.175 Torr each, RF power of $10 \mathrm{~W}$ and $2 \mathrm{~W}$, deposition time of $20 \mathrm{~min}$ and $25 \mathrm{~min}$. The flow rate of $1.98 \% \mathrm{~B}_{2} \mathrm{H}_{6}$ in $\mathrm{H}_{2}$ flow is $20 \mathrm{sccm}$ for p-doped and the flow rate of $1.88 \% \mathrm{PH}_{3}$ in $\mathrm{H}_{2}$ flow is $20 \mathrm{sccm}$ for $\mathrm{n}$ doped a-Si:H. For characterization of film conductivity parameters, $n$-type and $p$-type films were deposited on glass substrates. These substrates were cleaned in the same manner as the glass rods. The deposition parameters also remained the same, except the $p$-type film was deposited for $30 \mathrm{~min}$.

Silicon electronic parameters. To measure the a-Si:H film conductivity, transmission line measurements were performed, with pad sizes of $2 \mathrm{~mm}$ (width) $\times 2.5$ $\mathrm{mm}$ (Length) with gaps varying from 0.2 to $0.6 \mathrm{~mm}$ in steps of $0.1 \mathrm{~mm}$. For the p-type film, $300 \mathrm{~nm}$ thick aluminum contacts were deposited using RF sputtering ( $300 \mathrm{~W}, 5.0 \mathrm{mTorr}$, Ar flow rate of $20 \mathrm{sccm})$. For the $n$-type film, silver contacts were deposited using the same method $(300 \mathrm{~W}, 5.0 \mathrm{mT}$ Torr, Ar flow rate of $20 \mathrm{sccm})$. Doping concentration and mobility were not measured. Instead, the doping percentage was estimated using the fit line from a previous study on PECVD doping efficiency. We also expect the density of amorphous silicon to be in the range of $0.7-0.9$ of the density of crystalline silicon, so 0.8 was taken as an average value. The atomic density of silicon is $5.0 \times 10^{22} \mathrm{~cm}^{-3}$. Multiplying these gives us the expected doping concentrations. The mobility was estimated with $\sigma=$ $q \mu n$. The $\mathrm{n}$-type and p-type have carrier concentrations and mobilities respectively as $3.9 \times 10^{18} \mathrm{~cm}^{-3}$ and $1.5 \times 10^{-3} \mathrm{~cm}^{2} \mathrm{~V}^{-1} \mathrm{~s}^{-1}, 8.5 \times 10^{18} \mathrm{~cm}^{-3}$, and $5.3 \times 10^{-5} \mathrm{~cm}^{2} \mathrm{~V}^{-1} \mathrm{~s}^{-1}$. The estimated mobilities are comparable to those reported 
in the literature. The mobility of holes in amorphous silicon is well established as being orders of magnitude lower than that of electrons.

Simulated quantum efficiency. In order to simulate the quantum efficiency spectrum of a back-illuminated $p$-type/ $n$-type/Indium oxide stack, we employed Solcore, which is a comprehensive solar cell simulation package, with the stack of $p$-type amorphous silicon as the emitter, $n$-type amorphous silicon as the base, and Indium oxide stack as the window. The dopant concentration of the $30 \mathrm{~nm}$ thick $n$ type is $3.9 \times 10^{18} \mathrm{~cm}^{-3}$ and $8.5 \times 10^{18} \mathrm{~cm}^{-3}$ for the $200 \mathrm{~nm}$ thick $p$-type layer. In order to determine the equilibrium bandgap of the $\mathrm{p} / \mathrm{n} / \mathrm{In}_{2} \mathrm{O}_{3}$ junction, a $1 \mathrm{D}$ Poisson equation solution was implemented in Python, with the amorphous silicon dopant concentration of $4 \times 10^{18} \mathrm{~cm}^{-3}$ (n-type) and $9 \times 10^{18} \mathrm{~cm}^{-3}$ ( $p$-type), with $\mathrm{In}_{2} \mathrm{O}_{3} n$-type dopant averaged concentration of $1 \times 10^{16} \mathrm{~cm}^{-3}$ as determined from Hall mobility measurements in prior work (ranges from $5.2 \times 10^{15} \mathrm{~cm}^{-3}$ to $1.4 \times$ $10^{16} \mathrm{~cm}^{-3}$ over the temperature range from ambient to $150{ }^{\circ} \mathrm{C}$ under photoillumination)

Experimental quantum efficiency. The amount of photon energy absorbed by the $\mathrm{In}_{2} \mathrm{O}_{3-x}(\mathrm{OH})_{y}$ coating is approximated by $N_{a p h}=\left(E(\lambda) \times A_{\text {rod }}\right) / U_{\lambda}$; where $E(\lambda)$ represents the fractional difference in light intensity transmitted by the coated and uncoated rod and can be determined by integrating the arc lamp spectrum with the transmittance spectra of the coated or uncoated rod shown in Supplementary Fig. 15 and Fig. $3 e, A_{\text {rod }}$ is the surface area of the rod excluding the ends, and $U_{\lambda}=\int_{\lambda_{2}}^{\lambda_{1}}\left(h . c \times N_{A}\right) / \lambda d \lambda$ is the photon energy (J/mol photon) summed over the UV-visible regime over the xenon-arc lamp, where $h$ is the Planck constant $\left(6.626 \times 10^{-34} \mathrm{~J} \mathrm{~s}\right), c$ the speed of light $\left(3 \times 10^{8} \mathrm{~m} / \mathrm{s}\right)$ and $N_{A}$ is Avogadro's number $\left(6.022 \times 10^{23} \mathrm{~mol}^{-1}\right)$.

EPR measurement. The EPR system was a custom instrument with $v=9342.4$ $\mathrm{MHz}$. By fitting the EPR signal with Easyspin, the concentration of spin states ( $G$ factor of 2.152 with a non-Gaussian linewidth of 5.3) increased to $160 \%$ of the dark spin concentration after an hour of illumination and decays sub-linearly after turning off photo-illumination. Indeed, the concentration of spin states remains high at $121 \%$ of the dark concentration after $200 \mathrm{~min}$, thus indicating a slow release of photo-ionized oxygen vacancies to neutral oxygen vacancies. Extrapolating the decay trend shows that it will take $410 \mathrm{~min}$ after turning off photo-illumination to reach the original dark concentration of spin states.

\section{Data availability}

All data were available upon reasonable request.

\section{Code availability}

All code available upon reasonable request.

Received: 3 June 2020; Accepted: 3 December 2020;

Published online: 15 January 2021

\section{References}

1. Studt, F. et al. The mechanism of $\mathrm{CO}$ and $\mathrm{CO}_{2}$ hydrogenation to methanol over Cu-based catalysts. ChemCatChem 7, 1105-1111 (2015).

2. Wang, W., Wang, S. P., Ma, X. B. \& Gong, J. L. Recent advances in catalytic hydrogenation of carbon dioxide. Chem. Soc. Rev. 40, 3703-3727 (2011).

3. Wernicke, H. J., Plass, L. \& Schmidt, F. Methanol: The Basic Chemical and Energy Feedstock of the Future. (ed M. Bertau) (Springer, 2014) ISBN 978-3642-39709-7.

4. Olah, G. A., Goeppert, A. G., Prakash, K. S. Beyond Oil and Gas: The Methanol Economy, Second Edition. (Wiley-VCH Verlag GmbH \& Co. KGaA, 2006) ISBN:9783527324224.

5. Bukhtiyarova, M., Lunkenbein, T., Kähler, K. \& Schlögl, R. Methanol synthesis from industrial $\mathrm{CO}_{2}$ sources: a contribution to chemical energy conversion. Catal. Lett. 147, 416-427 (2017).

6. Dilla, M., Mateblowski, A., Ristig, S. \& Strunk, J. Photocatalytic $\mathrm{CO}_{2}$ reduction under continuous flow high-purity conditions: influence of light intensity and $\mathrm{H}_{2} \mathrm{O}$ concentration. ChemCatChem 9, 4345-4352 (2017).

7. Deng, Y. Developing a Langmuir-type excitation equilibrium equation to describe the effect of light intensity on the kinetics of the photocatalytic oxidation. Chem. Eng. J. 337, 220-227 (2018).

8. Kasap, S. O. Principles of Electronic Materials and Devices: Chapter 5. (McGraw-Hill, 2007) ISBN 978-0-07-064820-3.

9. Bloh, J. Z. A holistic approach to model the kinetics of photo-catalytic Reactions. Front. Chem. 7, 128 (2019).
10. Serpone, N. \& Salinaro, A. Terminology, relative photonic efficiencies and quantum yields in heterogeneous photocatalysis. Pure Appl. Chem. 71, 303-320 (1999).

11. Choi, W., Ko, J. Y., Park, H. \& Chung, J. S. Investigation on $\mathrm{TiO}_{2}$-coated optical fibers for gas-phase photocatalytic oxidation of acetone. Appl. Catal. B 31(3), 209-220 (2001).

12. Ma, C. M., Wang, W., Ku, Y. \& Jeng, F. T. Photocatalytic degradation of benzene in air streams in an optical fiber photoreactor. Chem. Eng. Tech. 30 (8), 1083-1087 (2007)

13. Ma, C., Ku, Y., Chou, Y. \& Jeng, F. Performance of tubular-type optical fiber reactor for decomposition of VOCs in gaseous phase. J. Environ. Eng. Manag. 18(6), 363-369 (2008)

14. Kho, E. T. et al. A review on photo-thermal catalytic conversion of carbon dioxide. Green. Energy Environ. 2(3), 204-217 (2017).

15. Daza, Y. A. \& Kuhn, J. N. $\mathrm{CO}_{2}$ conversion by reverse water gas shift catalysis: comparison of catalysts, mechanisms and their consequences for $\mathrm{CO}_{2}$ conversion to liquid fuels. RSC Adv. 55, 49675-49691 (2016).

16. Smith, R. J. B., Loganathan, M. \& Shantha, M. S. A review of the water gas shift reaction kinetics. Int. J. Chem. React. Eng. 8, 1 (2010).

17. Hou, W. \& Cronin, S. B. A review of surface plasmon resonance-enhanced photocatalysis. Adv. Funct. Mater. 23(13), 1612-1619 (2013).

18. Hoch, L. B. et al. The rational design of a single-component photocatalyst for gas-phase $\mathrm{CO}_{2}$ reduction using both UV and visible Light. Adv. Sci. 1(1), 1-10 (2014).

19. Ghuman, K. K. et al. Illuminating $\mathrm{CO}_{2}$ reduction on frustrated Lewis pair surfaces: investigating the role of surface hydroxides and oxygen vacancies on nanocrystalline $\operatorname{In}_{2} \mathrm{O}_{3-\mathrm{x}}(\mathrm{OH})_{y}$. Phys. Chem. Chem. Phys. 17(22), 14623-14635 (2015).

20. Ghuman, K. K. et al. Surface analogues of molecular frustrated Lewis pairs in heterogeneous $\mathrm{CO}_{2}$ hydrogenation catalysis. ACS Catal. 6(9), 5764-5770 (2016).

21. He, L. et al. Spatial separation of charge carriers in $\operatorname{In}_{2} \mathrm{O}_{3-\mathrm{x}}(\mathrm{OH})_{\mathrm{y}}$ nanocrystal superstructures for enhanced gas-phase photocatalytic activity. ACS Nano. 10 (5), 5578-5586 (2016).

22. Loh, J. Y. Y. \& Kherani, N. P. In situ electronic probing of photoconductive trap states for the catalytic reduction of $\mathrm{CO}_{2}$ by $\operatorname{In}_{2} \mathrm{O}_{3-\mathrm{x}} \mathrm{OH}_{\mathrm{y}}$ nanorods. J. Phys. Chem. Lett. 10, 526-532 (2019).

23. Ye, J., Liu, C., Mei, D. \& Ge, Q. Active oxygen vacancy site for methanol synthesis from $\mathrm{CO} 2$ hydrogenation on In2O3(110): a DFT study. ACS Catal. 3 (6), 1296-1306 (2013)

24. Zhuang, Z. B., Peng, Q., Liu, J. F., Wang, X. \& Li, Y. D. Indium hydroxides, oxyhydroxides, and oxides nanocrystals series. Inorg. Chem. 46(13), 5179-5187 (2007).

25. Berengue, O. M. et al. Structural characterization of indium oxide nanostructures: a Raman analysis. J. Phys. D 43, 4 (2010).

26. Joo, $\mathrm{H}$. A simple technique to determine quantum yield for UV photocatalytic decomposition studies. Kor. J. Chem. Eng. 23, 931-934 (2006).

27. Hoch, L. B. et al. Carrier dynamics and the role of surface defects: designing a photocatalyst for gas-phase $\mathrm{CO}_{2}$ reduction. Proc. Natl Sci. Acad. USA https:// doi.org/10.1073/pnas.1609374113 (2016).

28. Ghuman, K. K. et al. Photoexcited surface frustrated Lewis pairs for heterogeneous photocatalytic CO2 reduction. J. Am. Chem. Soc. 138(4), 1206-1214 (2016).

29. Alonso-Álvarez, D., Wilson, T., Pearce, P., Führer, M. \& Farrell, D. Solcore: a multi-scale, Python-based library for modelling solar cells and semiconductor materials. J. Comput. Electron. 17, 1099-1123 (2018).

30. Poole, V. M., Huso, J. \& McCluskey, M. D. The role of hydrogen and oxygen in the persistent photoconductivity of strontium titanate. J. Appl. Phys. 123, 161545 (2018).

31. Viana, E. R., Gonzlez, J. C., Ribeiro, G. M. \& De Oliveira, A. G. Photoluminescence and high-temperature persistent photoconductivity experiments in $\mathrm{SnO}_{2}$ nanobelts. J. Phys. Chem. C 117(15), 7844-7849 (2013).

32. Gurlo, A., Ivanovskaya, M., Pfau, A. Weimar. \& Gopel, U. W. Sol-gel prepared $\mathrm{In}_{2} \mathrm{O}_{3}$ thin films. Thin Solid Films. 307, 288-293 (1997).

33. Peng, X. S. et al. Synthesis and photoluminescence of single-crystalline $\mathrm{In}_{2} \mathrm{O}_{3}$ Nanowires. J. Mater. Chem. 12, 1602-1605 (2002).

34. Brinzari, V. Mechanism of band gap persistent photoconductivity (PPC) in $\mathrm{SnO}_{2}$ nanoscrystalline films: nature of local states, simulation of PPC and comparison with experiment. Appl. Surf. Sci. 411, 437-448 (2017).

35. Schlomberg, H. et al. Structural insights into poly(heptazine imides): a lightstoring carbon nitride material for dark photocatalysis. Chem. Mater. 31(18), 7478-7486 (2019)

\section{Acknowledgements}

We thank Peter Brodersen for technical support with X-ray Photo-spectroscopy measurements. This work was supported via grants from Natural Sciences and Engineering 
Research Council of Canada-Discovery program, Ontario Research Fund-Research Excellence Program, and the University of Toronto.

\section{Author contributions}

Joel Y.Y. Loh designed, measured, and plotted all results contained herein. Joel Y.Y. Loh prepared the paper. Abhinav Mohan synthesized and coated $\operatorname{In}_{2} \mathrm{O}_{3-x}(\mathrm{OH})_{y}$ nanorods onto the cylindrical quartz rods and performed scanning electron microscopy on the surface of the coated nanorods. Andrew G. Flood did Plasma Enhanced Chemical Vapor Deposition of doped amorphous silicon on the glass waveguides rods. Nazir P. Kherani and Geoffrey A. Ozin jointly supervised the work and edited the paper.

\section{Competing interests}

The authors declare no competing interests.

\section{Additional information}

Supplementary information is available for this paper at https://doi.org/10.1038/s41467020-20613-2.

Correspondence and requests for materials should be addressed to G.A.O. or N.P.K.
Peer review information Nature Communications thanks the anonymous reviewer(s) for their contribution to the peer review of this work.

Reprints and permission information is available at http://www.nature.com/reprints

Publisher's note Springer Nature remains neutral with regard to jurisdictional claims in published maps and institutional affiliations.

\section{cc) (i)}

Open Access This article is licensed under a Creative Commons Attribution 4.0 International License, which permits use, sharing, adaptation, distribution and reproduction in any medium or format, as long as you give appropriate credit to the original author(s) and the source, provide a link to the Creative Commons license, and indicate if changes were made. The images or other third party material in this article are included in the article's Creative Commons license, unless indicated otherwise in a credit line to the material. If material is not included in the article's Creative Commons license and your intended use is not permitted by statutory regulation or exceeds the permitted use, you will need to obtain permission directly from the copyright holder. To view a copy of this license, visit http://creativecommons.org/licenses/by/4.0/.

(C) The Author(s) 2021 